\title{
LOS PLANES DE IGUALDAD EN ESPAÑA: respuestas locales con perspectiva de género a problemas globales
}

\author{
Belén Blázquez Vilaplana*
}

\section{Resumen}

El objetivo del presente trabajo es presentar una reflexión sobre lo que ha significado la implementación de las políticas públicas de igualdad en España desde la reinstauración democrática, sobre todo, en el nivel administrativo local y a través de los conocidos planes de igualdad. Preguntarnos si todos esos avances que se dicen que han conseguido las mujeres al ser consideradas ciudadanas de pleno derecho realmente se han transformado en acciones concretas o siguen imperando los roles y estereotipos que las han invisibilizado como colectivo y como sujetas individualizadas. Recordar de dónde venimos siempre nos ayuda a no olvidar dónde estamos y cuántas lágrimas, esfuerzos y sacrificios nos ha costado llegar a ser escuchadas y tenidas en cuenta. Ese repaso, es lo que pretendemos con este trabajo en el ámbito del estado español.

Palabras-clave: Políticas públicas de igualdad. Estudios de género. Derechos humanos. Planes de igualdad. Administración local.

\section{Algunas notas introductorias ${ }^{1}$}

Cuando ya han pasado más de diez años desde que comenzó el siglo XXI y nos paramos a reflexionar sobre lo que significan los planes de igualdad y su aplicación en el ámbito local no podemos olvidar, si queremos entender el motivo último de su razón de ser, que hace apenas 75 años, las mujeres en España no podían votar en unas elecciones. Que todos los derechos que hoy se han alcanzado - o que algunas creen haber alcanzado - y las medias de las cuales tan orgullosos y orgullosas nos sentimos, eran una utopía a comienzos no ya del siglo pasado, sino en los años cincuenta del mismo. En treinta años, los que han

\footnotetext{
* Professora Doutora da Universidad de Jaén - Espanha. E-mail: bblazquez@ujaen.es.

${ }^{1}$ Quisiera agradecer las indicaciones y sugerencias que se me han hecho llegar por parte de los/las revisores anónimos de la revista. Y quedo abierta a cuantas sugerencias, comentarios y opiniones puedan suscitarse a raíz de su lectura.
} 
transcurrido desde que el dictador Francisco Franco murió y se reinstauró el sistema democrático, la mujer en España ha dado un salto sustancial desde, por ejemplo, la necesidad de contar con la firma de su pareja para poder abrir una cuenta en el banco o de no poder acceder libremente a los medios anticonceptivos que le han permitido disfrutar de su sexualidad, hasta la posibilidad de decir, al menos decir (lo cual no quiere decir que la escuchen), que hoy ya no hay nada que la diferencie de sus parejas en temas legales, por citar un ejemplo.

No podemos negar que los avances han sido importantes, para muchas y muchos o incluso impensables para la mayoría hace unos años. Ello a pesar de las dificultades que los mismos han supuesto y del camino que aún queda por recorrer. Por cuanto, existe un desfase, innegable, entre lo que se está legislando y lo que está ocurriendo en el día a día, mírese, por ejemplo, la persistencia de las diferencias salariales entre hombres y mujeres en el mercado laboral español ${ }^{2}$ o el tema de la violencia de género, en el cual no se consigue disminuir el número de mujeres que son asesinadas por sus parejas o ex parejas, sino todo lo contrario, ya que aunque la norma se ha aprobado los cambios de roles y los cambios educativos son mucho más lentos en el tiempo de conseguir. En este sentido, en el año 2009 fueron asesinadas en España 55 mujeres y en el 2010, 73. ${ }^{3}$ En la introducción del "Plan Estratégico de Igualdad de Oportunidades 2008-2011” aprobado por el Instituto de la Mujer, se menciona que los cambios culturales necesitan décadas para poder materializarse. Porque España aún se encuentra impregnada de estereotipos y roles de género que colocan a las mujeres en una situación de desventaja con respecto a los hombres y, dificultan el disfrute completo de sus derechos como ciudadanas. Discriminación que en un momento como el actual es imposible de aceptar por una sociedad que aspira a ser avanzada y moderna, debido a que es impensable prescindir de la capacidad, la inteligencia y la contribución de la mitad de su ciudadanía ${ }^{4}$. Ya que muchas veces, en muchos momentos, lugares y espacios, se ha olvidado, enterrando en la invisibilidad y en el más absoluto de los desprecios las contribuciones en

\footnotetext{
${ }^{2}$ Según la Encuesta de Estructura Salarial de 2008, publicada el 24 de Junio de 2010, en España esta diferencia es del 21,9\% ya que la ganancia media anual masculina es de 24.203,33 y la femenina de 18.910. Informe Sobre Discriminación Salarial; Instituto de la Mujer. 2010.

${ }^{3}$ Ley Orgánica 1/2003, de 28 de diciembre, de Medidas de Protección Integral contra la Violencia de Género. Según el Ministerio de Igualdad, la violencia de género: “nace de la desigualdad y las relaciones de poder de los hombres sobre las mujeres, y se ejerce por quienes sean o hayan sido sus cónyuges o estén o hayan estado vinculados a ellas por relaciones afectivas, aún sin convivencia”. Para mayor información véase: Informe sobre Víctimas mortales de la violencia de género y de la violencia doméstica en el ámbito de la pareja o expareja en 2010; Consejo General del Poder Judicial; Sección del Observatorio contra la Violencia de Género. <http://www.observatorioviolencia.org/upload_images/File/DOC1306844610_victimas_2010.pdf> (visitado el 31 de mayo de 2011)

${ }^{4}$ Para mayor información véase http://www.inmujer.es.
} 
distintos campos del saber y del conocimiento de la mujer, en singular y, sobre todo, de las mujeres en plural. Reclamemos pues la mitad, al menos la mitad del firmamento, porque somos más de la mitad del mundo, más que a algunos y también a algunas les pese.

Pero, mientras se han ido consolidando avances legislativos sobre la igualdad, se han ido produciendo también nuevas demandas de algunos sectores de la sociedad que no aceptan los derechos que se han ido consolidando en España en estos 30 años en relación a la igualdad. Grupos que alzan la voz ante las injusticias que según ellos se están cometiendo al aprobar medidas de acción positiva, cuotas para el acceso a algunas profesiones o posiciones de poder o leyes para luchar contra la violencia de género, entre otras, porque consideran que las mismas son discriminatorias para los hombres. Así, es posible encontrar numerosas afirmaciones sobre estos miedos, a los que denominaremos “irracionales” ${ }^{5}$, por cuanto no tienen una base ideológica, ni material, sino que su fin último es impedir los logros y parar las aspiraciones que se han ido consiguiendo en estas últimas décadas. Se ha atacado impunemente a lo que denominan fundamentalismo de género o feminismo radical, así Diego de los Santos, afirma que el varón nace culpable y se le somete a una sistemática discriminación en sus derechos esenciales, discriminación amparada en la neo "perspectiva de género" (2010, Prólogo).

Que hemos avanzado, por tanto, es innegable, que aún queda mucho por avanzar, creo que a nadie se le escapa, los datos cantan por sí solos como ahora veremos. Pero en estos temas, en la consolidación de los derechos de las mujeres, en su concreción, en su identificación como derechos humanos, no se puede dar un paso hacia atrás "ni para tener más espacios”. Cualquier mínimo resquicio que dejemos abierto posibilita un espacio para justificar recortes en los derechos que tantos años han tardado las mujeres en alcanzar y que tantos silencios han escondido. Los cambios que han posibilitado que hoy se pueda dialogar y exponer qué quieren las mujeres, qué anhelan, a qué aspiran, son el resultado de las

\footnotetext{
${ }^{5}$ Lo califico como tal, y entrecomillas, porque es miedo a perder sus privilegios, a dejar de ocupar ese espacio de poder en la sociedad (tanto en el ámbito privado como público) que tradicionalmente han tenido los hombres en España. Porque el discurso que mantienen es que las feministas tienen una posición de revancha hacia ellos, para desbancarlos de donde histórica, cultural y naturalmente deben estar. Es lo que se ha calificado como neomachismo. La Ministra de Igualdad, Bibiana Aído, comentaba sobre este tema que: Cuanto más avanzamos más nos atacan. He escuchado muchas veces esa frase de "qué más queréis". Atacan las políticas de igualdad porque cuestionan el orden establecido, y a la ministra de Igualdad la atacan porque no pueden soportar que una mujer joven y de pueblo pueda ocupar un sillón en el Consejo de Ministros porque ellos consideran que el poder es algo que les pertenece (...) el ataque permanente a las políticas de igualdad, esa permanente ridiculización busca trasladar el mensaje de que estas políticas no son importantes, que son un lujo prescindible. Diario El País, 18/07/2010.
} 
reivindicaciones de otras muchas mujeres que las antecedieron ${ }^{6}$. Aunque para algunas mujeres, esas que forman y formarán parte de las nuevas generaciones, las cosas les vengan “dadas” y, a veces, consideren que hoy están como están porque, sencillamente, “es lo que hay”. Es decir, no perciben que sus derechos y sus posibilidades reales de trabajo, educación, etcétera son consecuencia de los logros de los movimientos de otras que les antecedieron. Este es el caso de muchas mujeres en España ${ }^{7}$.

Lógicamente, no siempre se ha contado con los derechos y las posibilidades que hoy dibuja su discurrir diario. Y, sobre todo, no podemos olvidar que en muchas partes del mundo no son tal y como nosotras conocemos en nuestras realidades más cercanas, para algunas o muchas las cosas son muy diferentes, incluso en nuestra realidad más inmediata. Por ello, se debe luchar, se debe seguir luchando para que lo masculino deje de ser considerado como referencia universal y medida de la experiencia humana ${ }^{8}$. De ahí que el mero reconocimiento de los derechos no sea suficiente pero es un primer gran paso para todas las que reivindican que el hecho de nacer mujer no debe condicionar la profesión que puedan desarrollar, los caminos "formativos" que puedan realizar, las aspiraciones que puedan tener... para que el hecho de ser mujer, no de lugar a que en una demanda de divorcio aparezca la circunstancia de no saber cocinar como justificación de una reclamación de custodia ${ }^{9}$. Hecho que aunque podría parecer de la época franquista, es decir de la España de los años cincuenta, es de comienzos del siglo XXI. Por tanto, un claro ejemplo de mantenimiento de estereotipos y roles asociados a la figura femenina en la sociedad.

El objetivo de este trabajo es profundizar y dar a conocer una de las herramientas más novedosas que tenemos en la sociedad española para conseguir esa igualdad de género: los planes de igualdad a nivel local ${ }^{10}$. Para ello, iremos avanzando temporal y territorialmente,

\footnotetext{
${ }^{6}$ Muchas de ellas de las que desconocemos sus nombres y apellidos, o dónde vivieron y en qué momento, pero que contribuyeron con su existir a que hoy podamos reflexionar sobre qué es ser mujer. Véase, por ejemplo, Álvarez, María Teresa (2005); “Ellas mismas. Mujeres que han hecho historia contra viento y marea”; La Esfera de los Libros; Madrid.

${ }^{7}$ Según Erick Pescador: "En los años ochenta, el movimiento feminista y de igualdad fue más fuerte, a la generación que crecía entonces le quedó el discurso, pero los cambios dejan de producirse cuando se piensa que se han alcanzado (...) Las primeras frases que oye cuando inicia sus talleres de igualdad son: "Otra vez con ese tema. Pero ¿qué quieren las mujeres? Y, desgraciadamente, vuelven a ver el feminismo como lo opuesto al machismo: El feminismo es la lucha por la igualdad". Diario "El País”, 12/12/2007.

8 "Plan Estratégico de Igualdad de Oportunidades 2008-2001”, Instituto de la Mujer, Madrid, 2008.

${ }^{9}$ Divorcio Contencioso (N) 506/2007; NIG: 1808742C20070013701: “... la demandada, como consecuencia de su trabajo, no tiene tiempo ni costumbre de dedicarse a las labores domésticas y al cuidado de la hija. Hablamos de tareas tales como la limpieza y orden de la casa o hacer la comida... la demandada no sabe cocinar, más allá de hacer unos spaguettis en el caso de que el marido no esté en la casa para hacerse cargo de la comida”. Lo cual dio lugar a la Sentencia 506/2007, de 21 de abril de 2008. Juzgado de Primera Instancia n $^{\circ} 10$ de Granada (España)

${ }_{10}$ No podemos olvidar que tal y como recoge la Constitución Española de 1978, el Estado se organiza territorialmente en municipios, en provincias y en las Comunidades Autónomas que se constituyan. Todas estas
} 
mostrando las distintas normativas existentes tanto dentro como fuera de España, que han permitido que puedan implementarse y ejecutarse este tipo de medidas. Situaremos nuestro análisis en la época democrática y, sobre todo, tras el triunfo del gobierno socialista en los años 80 y el comienzo de lo que se conoció como feminismo institucional, cuyo primer elemento de referencia es la creación del Instituto de la Mujer estatal. Posteriormente, iremos exponiendo los logros alcanzados a nivel nacional, autonómico y local. Sin olvidar nunca, la referencia europea como marco normativo superior del ordenamiento jurídico español en cuestiones relacionadas con la igualdad. Todo ello, avalado por algunos datos sobre lo que se ha ido consiguiendo y lo que queda por conseguir, será la base conceptual para adentrarnos en el espacio local y en la implementación de los planes de igualdad en este nivel políticoadministrativo. No vamos a evaluar qué se ha conseguido, pero sí dibujar las líneas directrices que han permitido que los mismos aparezcan y configuren cuáles deben ser las políticas públicas de igualdad que deben materializar las reivindicaciones y las demandas que han sido bandera de los movimientos feministas en España: igualdad de trato salarial y laboral; igualdad de acceso al mercado laboral; igualdad de participación política; ley contra la violencia de género; ley sobre el aborto, entre otras. En un momento de cambio de gobierno tras las últimas elecciones generales donde existen numerosas incertidumbres acerca del cambio que van a tomar las medidas ya implementas y los derechos alcanzados en estos espacios $^{11}$. Todo ello, bajo el enfoque del análisis de las políticas públicas y de la perspectiva de género.

\section{¿Dónde estamos? ¿De dónde venimos?}

Las mujeres han llevado a cabo la mayor revolución de la historia sin realizar un solo disparo, a través de reivindicaciones, de protestas en silencio (porque no les dejaban otra opción en muchas ocasiones), intentando no alzar mucho la voz para "no molestar", de plantarse ante las injusticias, de reclamar lo que pensaban que tenían derecho... muchas veces solas, otras en su propia compañía, ahora, cada vez más, con algunos a su lado ${ }^{12}$. En este

entidades gozan de autonomía para la gestión de sus respectivos intereses (art. 137). En España existen en la actualidad 17 Comunidades Autónomas y dos ciudades autónomas (Ceuta y Melilla).

${ }^{11}$ El 20 de noviembre de 2011 tuvo lugar elecciones legislativas en España. El Partido Popular por mayoría absoluta (186 escaños de un total de 350 en el Congreso) ganaba las mismas tras ocho años de gobierno socialista.

12 Cynthia Cockburn (2009): “Mujeres ante la guerra. Desde donde estamos”. Editorial Icaria; Antrazyt; Barcelona. En dicha obra se afirma que a pesar de las diferencias y los distintos debates que existen sobre el 
punto queremos dejar constancia del amplio debate que se ha producido sobre cómo entender y aplicar los conceptos de igualdad versus diferencia de género, así como sobre la utilización de la categoría sexo versus género, o la denominación mujer o mujeres como categorías analíticas $^{13}$. En este sentido hemos planteado en otros trabajos, la reivindicación de la pluralidad semántica y científica de esta mayoría tratada como minoría a lo largo de la historia, las mujeres. Necesidad ineludible si lo que se busca es analizar y entender las políticas de igualdad con perspectiva de género ${ }^{14} \mathrm{y}$ los derechos y deberes asociados a las mismas $^{15}$.

En España estas reivindicaciones, a pesar de lo que aún queda por conseguir, tuvieron un punto de inflexión para los defensores de la igualdad como principio y valor central del funcionamiento del Estado de Bienestar con la creación del ya inexistente Ministerio de Igualdad tras las Elecciones Generales del $2004^{16}$. La revalidación del triunfo del Partido Socialista en la primavera del 2008, llevó al presidente del Gobierno, José Luís Rodríguez Zapatero, a la modificación de la estructura ministerial de la Administración General del Estado con la entrada de un ministerio que nadie había incluido en las quinielas durante la formación del ejecutivo ${ }^{17}$. Su novedad y, hasta cierto punto originalidad, se encontraba en el tema objeto del mismo: la Igualdad. No sólo entre géneros, como se ha querido poner sobre la mesa en algunos momentos para su descalificación y justificación de su innecesaria existencia, sino en el sentido más amplio de la palabra igualdad. Entre sus actividades, se encontró la puesta en marcha e implementación de las medidas recogidas en la Ley de

pacifismo, no es posible entender la guerra, ni hacer una campaña efectiva contra la misma, sin tener como referencia el poder y la violencia de género.

${ }^{13}$ Paradojas que son puestas de relieve en el artículo de J. Scott: "O feminismo foi um protesto contra a exclusão das mulheres da política; seu objetivo foi o de eliminar a diferença sexual na política. Mas a sua campanha foi voltada às mulheres. Pelo fato de agir em favor das mulheres, o feminismo produziu a diferença sexual que buscava eliminar - chamando a atenção exatamente para a questão que pretendia eliminar". Véase para mayor información el trabajo de J. Scott en Revista de Estudos Feministas: “O enigma da igualdade”, no 13, pp 13-30, 2005.

${ }^{14}$ Blázquez Vilaplana, Belén (2010): "Los estudios de género desde una visión politológica: la perspectiva de género como generadora de nuevos ámbitos de conocimiento y reflexión en España” en Delgado de Smith, Y. y María Cristina González: Mujeres en el mundo: colonialismo, racismo, redes, violencia de género, política y ciudadanía. Lainet. Valencia. Venezuela.

${ }^{15}$ Las preguntas serían: ¿Puede una mujer representar a todas las mujeres, más allá de sus diferencias étnicas, sociales, económicas, generacional, etcétera? ¿Estudios de mujeres y sobre mujeres o estudios de género y con perspectiva de género? ¿Mujer como categoría biológica o mujer entendida como categoría de catalogación sociológica?

${ }^{16}$ Existen numerosa referencias bibliográficas acerca de la situación de las mujeres y de los movimientos feministas en los primeros años de la transición política española. Entre otros, véase: Judith Astelarra (2005); "Veinte años de políticas de igualdad"; Madrid. Editorial Cátedra Feminismos. Pilar Folguera (ed) (2007); "El feminismo en España. Dos siglos de Historia"; Fundación Pablo Iglesias; Madrid. Asociación "Mujeres en la transición democrática” (1999): Españolas en la transición. De excluidas a protagonistas (1973-1982). Madrid: Biblioteca Nueva

${ }^{17}$ Diz Otero, Isabel y Lois González, Marta (eds) (2007); “Mujeres, instituciones y política”; Edición Bellatera y Escola Galega de Administración Pública; Barcelona 
Igualdad Efectiva entre Mujeres y Hombres ${ }^{18}$ del 2007, las de la Ley Integral contra la Violencia de Género ya mencionada anteriormente y la de los planes y actuaciones del Instituto de la Mujer y del Instituto de la Juventud. Centrándose, entre otras cuestiones, en la creación de empleo para las mujeres, equiparación salarial e incremento de las oportunidades para las más jóvenes. Antes de su desaparición se centró en la modificación de la Ley del Aborto y temas relacionados con la Prostitución y la trata de mujeres. ${ }^{19}$

Pero, la sorpresa inicial que produjo su creación, se vio acompañada desde el principio por una amplia polémica, con posturas a favor y en contra no tanto de su necesidad o posible operatividad en un contexto como el actual de crisis económica, sino, sobre todo, por la persona que se puso al frente del mismo. Las primeras críticas se personificaron en quién debía gestionar el Ministerio de Igualdad, las cuales no le abandonaron a lo largo de los años en que el mismo se mantuvo en el organigrama ministerial. En este sentido, Bibiana Aído Almagro $^{20}$, la Ministra de Igualdad, (Alcalá de los Gazules, 1977), se convirtió en la ministra más joven de la historia de la democracia española y en el objeto de las mayores críticas, no por su gestión sino por otras cuestiones que guardaban más relación con el hecho de ser mujer, joven y trabajar en un campo que había sido elegido como bandera de la política del actual gobierno: la igualdad de género. Algunos, o muchos, quisieron desde el mismo día de su nombramiento valorar éste en función de su edad y de su, para algunos, falta de “currículum” para ser Ministra. Temas que en otros casos nunca se habían cuestionado, al menos, no con la simpleza que entendemos que se hizo desde que se conoció por la opinión pública a quién había designado el Presidente Zapatero. Muchos se dirigían a este Ministerio como el de "Igual - da” y atacaban sistemáticamente cualquier actuación o declaración de su titular.

La mayor parte de las críticas que recibió tuvieron dos ejes, por una parte la “necesidad” que tenía el Presidente de cubrir la cuota de género femenino ${ }^{21}$, la cual había

\footnotetext{
${ }^{18}$ Ley Orgánica 3/2007 de 22 de marzo, para la igualdad efectiva de mujeres y hombres, fue aprobada por las Cortes Generales de España, y publicada en el BOE no 71 de 23/3/2007

${ }^{19}$ En una de las primeras entrevistas que se le realizó tras su llegada al gobierno decía que su ministerio servía: Para pasar de la igualdad legal a la igualdad real efectiva. Sobre las leyes pesan los usos, las costumbres, las inercias. Es una apuesta política de primer nivel del presidente del Gobierno. Aunque en ningún caso éste va a ser un ministerio especialmente inversor. Su misión es hacer efectivo ese principio de transversalidad que tiene que aplicarse a todas las políticas públicas y a todos los actos del Gobierno. Diario "El País", 18/08/2008

${ }^{20}$ Antes de ser nombrada Ministra fue delegada provincial de la Consejería de Cultura de la Junta de Andalucía en Cádiz, entre febrero de 2003 y julio de 2006 y Directora de la Agencia Andaluza para el Desarrollo del Flamenco en la Consejería de Cultura entre julio de 2006 y marzo de 2008. Está afiliada al PSOE desde 1995, siendo candidata al Parlamento Andaluz por la provincia de Cádiz en 2000 y en 2008.

${ }^{21}$ La lectura simplista que se hacía es que se había tenido que busca una mujer para cubrir ese puesto y, ese hecho - que tenía que ser mujer - era el único requisito importante e incuestionable. Es decir, que no importaba
} 
defendido durante toda la campaña electoral y, por otra, la de dar mayor presencia en el ejecutivo a la fuerte “delegación” de una de las Comunidades Autónomas con mayor peso en España, Andalucía. Y esos dos requisitos los reunía en su persona la Ministra de Igualdad. Antes, hasta hace unos años, casi había que pedir perdón por ser mujer y querer dedicarse a la política, ahora había que unir dos variables más, por un lado la juventud (la cual más que a algunos les pese se cura con el tiempo y con el trabajo, en el caso de la supuesta falta de experiencia) y, por otra, con la de ser consideradas "mujer cuota”. Crítica que procedía tanto de la clase política masculina, como de la femenina perteneciente a la derecha ideológica. Ellos - los hombres que se han dedicado a la política - nunca han debido justificar su presencia en algún cargo, más allá de las típicas rencillas político-partidistas, las mujeres siguen teniendo que "pedir permiso para poder acceder”. Y si además lo hacen a través o en espacios donde existen cuotas, deben superar la connotación peyorativa que algunos le ven y de la cual la lectura que se hace es que han llegado a ocupar ese espacio de poder no porque merezcan estar ahí, por cuestiones meritocráticas, sino por cumplir un requisito numérico.

Se da con ello la razón a la reflexión de Soledad Murillo, hasta hace muy poco tiempo Secretaria General de Políticas de Igualdad del Gobierno español, la cual afirmaba que estas situaciones lo que mostraban era que las mujeres seguían siendo invitadas toleradas en el espacio público y no ciudadanas de pleno derecho. Cuando el presidente del Gobierno decidió eliminar el Ministerio, por razones presupuestarias - según se intentó justificar - Bibiana Aído siguió desempeñando el cargo de Secretaria de Estado para la Igualdad hasta que en junio del año 2011, fue nombrada asesora especial de la directora ejecutiva de ONU mujeres, Michele Bachelet ${ }^{22}$. Por tanto, no sólo aceptó seguir desempeñando un cargo en el cual había sido degradada políticamente de categoría, al pasar de Ministra a Secretaria de Estado, sino que cuando lo dejó fue para dar un salto a la política internacional. Es decir, la primera actitud, dio cuenta de un compromiso político y ético con los temas de igualdad y con la apuesta del gobierno socialista y la segunda, un reconocimiento a su trabajo y su valía personal y profesional.

\footnotetext{
su valía, sus conocimientos, su trayectoria política anterior... lo único que importaba era que en su carnet de identidad pusiera: mujer.

${ }^{22}$ Según se afirmó desde ONU Mujeres, Aído "ha trabajado extensamente para la transversalización de la igualdad en la política española, así como en la igualdad de género y la perspectiva de género en diversos foros internacionales, tales como la UE para la promoción de la estrategia europea y el Observatorio Europeo contra la Violencia de Género". Diario El País, 28/6/2011
} 
Consideramos que la creación de dicho Ministerio ${ }^{23}$ pudo analizarse en su momento como el fin de un largo camino recorrido por muchos y muchas en España, pero, al mismo tiempo, como el punto de arranque hacia la consecución de una igualdad efectiva, real y sin matices. Algo distante, por tanto, de lo que había existido hasta el momento. La temática (o problemática) de la igualdad es, y así está recogido en diversos planes, legislaciones nacionales e internacionales, etcétera, un tema transversal. Cualquier medida que se apruebe y se lleve a cabo debe hacerse bajo este prisma. El hecho de que se crease una estructura con esta denominación no debería hacer que el resto de organismos públicos e instituciones, o la administración territorial competente no se preocupasen en su búsqueda y consecución. Lo cual, guarda estrecha relación con una de las críticas que recibió a lo largo de su mandato: la falta de presupuesto, el cual ascendía en su último año de funcionamiento, 2010, a 109.756.660 euros. Es cierto que en el momento de crearse apenas contaba con el montante necesario para poner en marcha acciones, medidas, programas pero, como se han encargado de clarificar sus responsables, ello era debido, sobre todo, a que no se consideraba un ministerio “inversor” ${ }^{24}$. Como se recoge en el Real Decreto 1135/2008 de 4 de julio, por el que se desarrolla la estructura orgánica básica del Ministerio de Igualdad, en su artículo 1:

1. Le corresponde la propuesta y ejecución de las políticas del Gobierno en materia de igualdad, eliminación de toda clase de discriminación de las personas por razón de sexo, origen racial o étnico, religión o ideología, orientación sexual, edad o cualquier otra condición o circunstancia personal o social, y erradicación de la violencia de género, así como en materia de juventud. Le corresponde, en particular, la elaboración y desarrollo de las normas, actuaciones y medidas dirigidas a asegurar la igualdad de trato y de oportunidades, especialmente entre mujeres y hombres y el fomento de la participación social y política de las mujeres.

2. Las competencias atribuidas en este real decreto se entenderán en coordinación con las que corresponden a otros departamentos ministeriales, dado su carácter transversal ${ }^{25}$.

\footnotetext{
${ }^{23}$ La estructura del citado Ministerio era: Gabinete de la Ministra; Subsecretaría de Igualdad - Secretaría General Técnica-; Secretaría General de Políticas de Igualdad - Delegación del Gobierno para la Violencia de Género; Dirección General para la Igualdad en el Empleo y contra la Discriminación; Además, existen una serie de Organismos públicos adscritos a este Ministerio: Instituto de la Juventud; Consejo de la Juventud de España y el Instituto de la mujer.

${ }^{24}$ En ese primer año su presupuesto era de 43 millones de euros.

${ }^{25}$ Entenderemos por Transversalización del enfoque de género el proceso de evaluar las diferentes implicaciones que cualquier iniciativa, incluyendo leyes, programas y políticas, en cualquier área o nivel, tendrá sobre las vidas de los hombres y las mujeres. Es una estrategia para hacer que los intereses, preocupaciones y experiencias de las mujeres y de los hombres constituyan una dimensión integral en el proceso de diseño, implementación, monitoreo y evaluación de políticas y programas en todas las esferas políticas, económicas y sociales, de manera que la desigualdad entre hombres y mujeres no se vea reproducida ni perpetuada.
} 
Por tanto, más allá de todos los matices que se puedan anotar sobre su existencia, entendemos que fue un elemento positivo y un logro para todas y todos los que durante tantos años habían luchado por la igualdad efectiva en España. Los símbolos son muy importantes para reflejar lo que se ha conseguido, lo que se ha avanzado en la consecución de políticas públicas de igualdad. La existencia de este Ministerio ha sido un símbolo, desde el que se ha estado luchando por conseguir una sociedad más igualitaria en general y, por que las mujeres dejen de estar en una situación de desventaja, en particular. Aunque según Rodríguez Zapatero, este Ministerio se mantendría por mucho tiempo, porque es el más austero de la historia, el más joven y el que siempre algunas voces han pedido que desaparezca, finalmente no fue así. Desgraciadamente, en octubre del 2010 las cosas cambiaron y el Ministerio desapareció en aras de una mayor eficiencia económica - así se argumento - siendo asumida sus actividades por otros Ministerios o Secretarías de Estado. Ello a pesar de que en ese momento sólo era el 0,0029\% de los Presupuestos Generales del Estado, 78 millones de euros. Supuso acabar con una de las grandes apuestas personales del Presidente del Gobierno y con ello de muchas de las esperanzas de las defensoras del mismo. Aquellas que durante los años de su funcionamiento se habían postulado por la necesidad de su existencia, la importancia para una sociedad que aspiraba a conseguir calidad democrática, gobernabilidad y equidad social, su desaparición fue un golpe difícil de encajar.

Las políticas públicas que este Ministerio se encargó de visibilizar, uno de sus principales logros, volvieron a considerarse de segunda categoría, adscritas y subrogadas a otros temas de interés nacional, prescindibles en momento de incertidumbre política. La lectura que desde algunos sectores se hizo de dicha disolución fue que en época de crisis económica y de dificultades, la igualdad pasaba a ser considerada un tema no prioritario para la articulación de la sociedad española. Y eso a pesar de que la propia Ministra había expuesto que los temas que iban a conformar la agenda de su Ministerio eran políticas necesarias para el progreso económico. Los datos están claros: aquellas empresas que incorporan a más mujeres en los ámbitos de decisión, que apuestan por políticas de conciliación, horarios flexibles, son las más productivas, las que tienen mejores resultados; y con los países lo mismo, los primeros en el ranking de competitividad son los primeros en el ranking de igualdad de género $^{26}$. A nivel nacional, por tanto, se contó con un efímero Ministerio de Igualdad, que sería transformado en Secretaría de Estado, dependiente del Ministerio de Sanidad y Política Social, del cual muchas veces se tenía conocimiento no tanto por lo que

\footnotetext{
${ }^{26}$ Entrevista con Bibiana Aído. Diario El País 18/08/2008.
} 
suponía y las acciones, campañas o actividades que realizaba, sino por cuestiones hasta cierto punto “anecdóticas”27. Pero que consiguió durante los tres años en que estuvo funcionando que la población española fuera consciente de la necesidad de trabajar para alcanzar la igualdad real de mujeres y hombres en todos los espacios públicos y privados. Algunas de las sendas que se abrieron se han mantenido después de que ya no existiera como tal en la estructura del gobierno nacional, favorecido por la permanencia del gobierno socialista al frente del ejecutivo ${ }^{28}$. En algunos casos luchando con la crisis económica, en otras con gobiernos autonómicos y/o locales de distinto signo político, pero en casi todos, apoyados por el trabajo y el esfuerzo de los movimientos feministas, las asociaciones de mujeres, los grupos de estudios de género, los seminarios...

Por otra parte, a nivel autonómico y local, con estructuras dentro de las Consejerías y de las entidades locales cuyo fin último es la actividad a favor de la consecución de esta igualdad que reclaman las mujeres, han proliferado en los últimos años, no sólo Institutos de la Mujer con distintas denominaciones ${ }^{29}$ sino también consejerías y concejalías, grupos de trabajo y profesionales cuyo objetivo es avanzar en la concreción de los derechos de ese otro más del cincuenta por ciento de la ciudadanía, las mujeres.

Para entender cómo se ha llegado a este momento, es necesario partir del siguiente supuesto: el tema de la desigualdad entre hombres y mujeres, del posicionamiento de la mujer en la sociedad, en la política, en el mundo laboral... se ha convertido en los últimos años en objeto de controversia pública, de interés para los legisladores y la sociedad civil y, por ende, en materia de las Políticas Públicas. Si en un principio, fue el tema de la discriminación el que ocupó los principales debates, en la actualidad ha sido la desigualdad el que ha obtenido numerosos avances para su erradicación tanto en el plano internacional, como posteriormente en el nacional.

\footnotetext{
${ }^{27}$ Un análisis detallado de la prensa nacional mostraría los numerosos titulares que, sobre todo en los primeros meses de su andadura, originó dicho Ministerio y la persona que encabezaba el mismo. En un artículo publicado por el Diario "El País” decía: "Para que Alfredo Pérez Rubalcaba, ministro del Interior, hubiese generado un volumen de comentarios sobre su atuendo el día de la Pascua Militar similar al de la Ministra de Defensa, probablemente tendría que haber acudido al acto vestido con una falda (...) en el escaño de diputada, en el sillón de ministra, arrastran aún el pecado original de ser mujeres y, en penitencia, se las despoja del apellido y se les pide explicaciones de cómo se visten, de cómo cuidan a sus hijos o por qué no los tienen”; $<$ http://www.elpais.es>. Acceso en 5 de mayo de 2011.

${ }^{28}$ El interrogante se abre ahora con el triunfo del Partido Popular en las elecciones legislativas por mayoría absoluta.

${ }^{29}$ En los últimos meses del 2010 se barajó la posibilidad - casi inmediata - de cerrar el de Murcia y el de Castilla La Mancha (ambas Comunidades Autónomas dirigidas por el Partido Popular) y son muchas las voces que se plantean qué ocurrirá si el Partido Popular, como vaticinan las encuestas, gana las próximas elecciones generales.
} 
Aunque las mujeres son, como ya se ha mencionado y como la mayor parte conoce, más del 50\% de la población mundial (en España estamos sobre el 507\%) aún siguen estando Infra representadas en numerosos espacios. La presencia de estas en el mundo de la política, en el mercado laboral, en los puestos de responsabilidad en las Universidades... es inferior al de los hombres y los avances son tan lentos como si las mujeres en lugar de piernas tuvieran "pies de tortuguitas”. Mucho se ha escrito sobre las razones de ello, sobre los obstáculos para que siga existiendo lo que se conoce como el techo de cristal o el suelo pegajoso, acerca de si hay o no un laberinto donde todas estamos - y ellos nunca entran-, sobre la necesidad de impulsar medidas de acción positiva - de apoyar la discriminación positiva- o de imponer cuotas en determinadas legislaciones, etcétera. Avanzamos, pero no siempre al ritmo que desearíamos, ni en el sentido que nos gustaría hacerlo.

Lo cierto es que en este comienzo de siglo, los avances han sido muchos, pero las barreras y lo que aún falta por alcanzar sigue siendo la razón última de las reivindicaciones de muchas mujeres y cada vez más de algunos hombres. La gran diferencia es que estos temas han dejado de pertenecer a la esfera privada y se han convertido en tema de interés de los poderes públicos y, por ende, objeto de debate en las instituciones políticas. Se han incluido en los programas de los distintos partidos políticos, son noticia en los medios de comunicación, son objeto de estudio de las Universidades y grupos de investigación, en una palabra, se han visualizado como problema público y político. Dando lugar a la necesidad de buscar respuesta a los mismos a través de lo que se conocen como Políticas Públicas y a su implementación de respuestas a estas demandas a través de los planes de igualdad, nacionales en un primer momento, autonómicos después y, en los últimos años, provinciales y locales. Es decir, existiendo una relación directa entre la estructura administrativa del Estado español y la proliferación de estas instituciones. Lo cual, en muchos momentos, más allá de ser un elemento a su favor, ha dado lugar a una duplicidad de recursos y de gastos.

\section{¿Q̨ué entendemos por políticas públicas de igualdad?}

Estas políticas públicas, y estos planes de igualdad de oportunidades, tendrían como punto de arranque la diferencia que se da en la sociedad entre lo que ésta percibe que existe y lo que se cree que debería de existir, entre lo que “es” y lo que “debería ser” en relación a la situación de la mujer, de sus posibilidades de actuación y de desarrollo, de su lugar en el mercado laboral o en los cargos de responsabilidad... pero no sólo de ella, porque su análisis 
bajo la perspectiva de género y con mirada transversal lo hace convertirse en un problema de la sociedad, de ésta en su conjunto, como un todo donde se compartan espacios, realidades y necesidades. Para que se haya avanzado en derechos ha sido necesario que a la mujer como colectivo se "la convierta” en un problema público en el sentido politológico del término. Nos enfrentaríamos a una diferencia, cuál es la realidad que hay, cuál nos gustaría que hubiera, que daría lugar a su vez a una problemática sociopolítica, la cual, para que pueda ser considerada por los poderes públicos, en sus distintos ámbitos territoriales - dependiendo del problema a tratar - deberá entrar en lo que se conoce como la agenda pública. La entrada en la agenda es el momento clave que determina que un tema sea tratado como política pública o no. Es decir, existen problemas sociales que pueden buscar respuesta en canales no gubernamentales, no públicos, no estatales. Para que se pueda decir que estamos hablando de Políticas Públicas, es necesario que sea alguna de las instituciones y/o poderes del Estado las que se involucren en alcanzar respuestas a las demandas ciudadanas. Los mecanismos para entrar en la agenda son variados pero pueden ir desde el propio interés del gobierno por tratar una temática determinada, hasta la presión de ciertos grupos o la intervención de los medios de comunicación. Existen problemas que siempre han formado y forman parte de la agenda gubernamental, conocida también como sistémica, mientras que otros, sólo lo hacen en momentos puntuales, dando lugar a las llamadas agendas institucionales que están compuestas por problemas sobre los que la autoridad pública tiene competencias, puede y quiere decidir, esto es, los que son objeto de una activa y seria consideración por parte de la autoridad pública. Hay situaciones que en determinados contextos, por determinadas cuestiones, pasan a convertirse en objetivo de interés por y para el Gobierno, lo cual deviene de la imposibilidad de que éstos puedan ocuparse y responder a todas las demandas planteadas por su ciudadanía $^{30}$. En este sentido, el lugar y la situación de la mujer, hoy día, comienzos del siglo XXI, lo es. En otras zonas del mundo, con mayor o menor éxito, con mayor o menor incidencia, también. ${ }^{31}$ Las mujeres se han convertido en un problema con aristas en los temas laborales, sociales, políticos, reproductivos... a los cuales ya era hora de buscar respuesta a través de canales públicos. Lo cual es un logro, más allá de si las mujeres se consideran o no, un problema. Su entrada en el mercado laboral, el cambio de roles y la ruptura de estereotipos que ello ha supuesto, la presencia en los espacios de poder, tanto a la hora de tomar decisiones

\footnotetext{
${ }^{30}$ Para mayor información, véase: Luis F. Aguilar Villanueva. Problemas públicos y agenda de gobierno. Ed. Miguel Ángel Porrua. México D.F. 1993.

${ }^{31}$ No es el objeto de este trabajo, pero sí debemos dejar constancia que los mismos van a depender de numerosas variables tales como la importancia de los movimientos feministas; la existencia de cuotas de participación política, social y/o económica; las nuevas legislaciones en temas de igualdad de género; el empoderamiento de las mujeres de esas sociedades, entre otras.
} 
como en el momento de plantear alternativas y llevarlas a cabo, entre otros factores, han permitido que las cuestiones en las que ellas eran consideradas como colectivo - más allá de las diferencias que ser mujer implica al ser analizadas bajo la perspectiva del género consiguieran pasar a formar parte de las agendas públicas y, por ende, a entender que la respuesta que se le diera a sus reivindicaciones, a sus demandas y luchas, debían ser articuladas a través de políticas públicas y responder a cómo se gestiona y se concibe el poder en la sociedad en la que se definen como ciudadanas. Donde el elemento vertebrador no es lo conseguido por ser mujer como antagónico o diferente a ser hombres, sino lo que se aprecia y se desprende de la aplicación de la perspectiva de género a la articulación de las políticas públicas.

Las mujeres han pasado de estar invisibilizadas en la mayor parte de la historia, a ser objeto de investigaciones, de expertos y master, de proyectos, de planes, políticas e instituciones. El ser mujer hoy en España “está de moda” $\mathrm{y}^{32}$, por tanto, se han convertido en objeto de interés para los poderes públicos. Pero ello tiene un riesgo y es que las modas, a veces, dejan de serlo y tendrán que estar alertas en que pasada la posible "euforia” de estos momentos, dejen de ser noticia no ya por haber alcanzado lo que reclaman por razón de justicia social, sino porque en una sociedad tan cambiante como la que nos ha tocado vivir, existan otros temas, otros colectivos, otras reivindicaciones, otras demandas, otras luchas que ocupen el espacio que hoy se les ha reservado a las mujeres, su espacio natural. En definitiva, el que siempre tuvieron que tener y el que aún muchos les quieren negar. Porque no podemos olvidar, ni dejar de tener como referente, que de lo que estamos hablando es de cómo se articula, se divide y se ejerce el poder en la sociedad.

En este momento, antes de saber qué es lo que ha posibilitado que las entidades locales centren parte de sus recursos humanos, financieros y administrativos en la elaboración e implementación de planes de igualdad hay que analizar de qué estamos hablando cuando nos enfrentamos a la situación de desigualdad de las mujeres en el mundo. Desgraciadamente, los datos apenas varían y en aquellos espacios en que se han logrado conquistas, hay que seguir trabajando en políticas antidiscriminatorias y en su defensa para no sufrir retrocesos ${ }^{33}$ :

- $2 / 3$ de las personas que viven bajo el umbral de la pobreza son mujeres

\footnotetext{
${ }^{32}$ En algunos casos parecía que es que las mujeres hasta ese momento no habían existido o no habían querido estar, nada más lejos de la realidad. Si no han estado, o no se las ha visibilizado es por el miedo a perder cuotas y espacios de poder. Por no querer compartir espacios en igualdad de condiciones y de oportunidad. En ello, al menos en el caso español que aquí nos ocupa, hay que destacar la importancia que los estudios de género realizados a través, sobre todo, de la esfera universitaria, han tenido.

${ }^{33}$ Cándida Gago (2006): Atlas de las Mujeres en el Mundo; Editorial SM. Recoge cartografía temática a escala mundial de las diferencias entre hombres y mujeres.
} 
- El 70\% de los casi 500 millones de analfabetas del mundo, son mujeres

- Más de 130 millones de mujeres sufren cada año mutilaciones genitales

- Dos millones de niñas entre 5 y 15 años se incorporan al mercado del sexo

- Se calcula que faltan en el mundo 72 millones de mujeres por la práctica de abortos selectivos, infanticidios, abandono de niñas recién nacidas o su desatención durante la niñez

- Son la mitad de los más de 40 millones de personas afectadas por el VIH en el mundo

El panorama no es muy alentador, aún así, si nos detenemos en ver la posición de la mujer en España en la actualidad, la situación parecería bastante idílica en relación a lo que había hace apenas 30 años: hemos tenido varios gobiernos paritarios a nivel nacional, y una mujer ha ocupado la Vicepresidencia del Gobierno, hay mujeres que ocupan carteras que tradicionalmente no se han considerado propias del género femenino (aunque me niego a que haya tal distinción, es decir, que haya cargos ministeriales que se consideren propios de un género y no de otro), ya sea Defensa o Fomento, hay mujeres frente a la Biblioteca Nacional, en algunas Reales Academias, en el Tribunal Constitucional. Los dos principales partidos han elegido a una mujer como portavoz parlamentaria y en algunas CCAA, incluso hay Parlamentos Autonómicos con mayor presencia de mujeres que de hombres y en algunos de sus gobiernos, también. En el año 2006, un estudio del Centro de Investigaciones Sociológicas ${ }^{34}$, decía que el $75 \%$ de las mujeres tenían que esforzase más que los hombres para demostrar que podían desempeñar un mismo puesto de trabajo y que en igualdad de condiciones la mayoría de las empresas preferían a hombres que a mujeres (aunque la mayoría, también, no estaban de acuerdo sobre el hecho de que en igualdad de condiciones se contratara a una mujer. En este aspecto, sí consideraban que se producía una violación de la Constitución española de 1978, donde se dice que todos los “españoles” - en masculino- son iguales ante la ley y de la igualdad de trato). Amparo Valcárcel decía que "la igualdad entre géneros llegará cuando las mujeres puedan cometer los mismos errores que los hombres y no se las insulte por ello". Veamos otra serie de datos que nos avalarían lo expuesto hasta el momento:

\footnotetext{
${ }^{34}$ Barómetro de Marzo del 2006, $\mathrm{n}^{\circ}$ de estudio 2636. Publicación: Opiniones y Actitudes CIS 60; REIS 135 y http://www.cis.es/cis/opencm/ES/1_encuestas/estudios/ver.jsp?estudio=5458 (Revisado Noviembre 2011). Temas de los que trata el estudio: Opinión sobre la situación actual de las desigualdades entre hombres y mujeres en España. Comparación con la situación hace diez años. Actitud hacia la igualdad de género. Acuerdo con frases sobre la importancia de la igualdad de género en la sociedad- Actitud hacia medidas o acciones para fomentar la igualdad de género en distintos ámbitos. Influencia. Conocimiento del Proyecto de Ley de Igualdad entre hombres y mujeres. Actitud. Conocimiento del Plan Concilia. Actitud.
} 
Por ejemplo, con relación a la participación política de la mujer, en España:

- Las mujeres son el 36\% del total en el Congreso y el 25¹\% en el Senado ${ }^{35}$. Siendo la media de la Unión Europea el 23\% (estamos en un quinto puesto, detrás de Suecia, Dinamarca, Holanda y Finlandia)

- Antes de las últimas elecciones municipales celebradas en mayo del 2011, había un $37 \%$ de concejalas en los Ayuntamientos y un 144\% de Alcaldesas, mientras que a nivel autonómico representan el 35’5\% del total de los gobiernos y el $41^{\prime} 11 \%$ de la presencia en los Parlamentos.

- En el Consejo General del Poder Judicial son el 10`5\%, un 5\% de las magistrados del Tribunal Supremo, un 16’7\% de las del Tribunal Constitucional, un 7’1\% del Tribunal de Cuentas y un 15’25 del Consejo Económico y Social

- Sólo somos el 5’8\% de las rectoras de las Universidades públicas españolas y apenas ocupamos el 3\% de la presidencia de las empresas del IBEX y el 3’7\% de las consejeras.

Con relación a la participación económica:

- Según los datos de la Encuesta de Estructura Salarial, el salario bruto anual medio femenino es un 28'9\% más bajo que el masculino, persistiendo las diferencias incluso en actividades feminizadas.

- Y ello, a pesar de que las mujeres han sido, hemos sido, las grandes beneficiarias de la Estrategia Europea de Empleo, siendo el 41'3\% del total de las personas ocupadas. Aunque, en un momento económico como el actual, tienen todas las papeletas para ser las que primero salgan del mercado laboral: trabajo a tiempo parcial, menos salario, etcétera. Más del 90\% de abandonos del mercado laboral por razones familiares corresponden a mujeres.

- Somos mayoría en las Universidades (sobre un 54\%) y obtenemos mejores resultados académicos, aunque también es cierto que seguimos copando carreras que aquí

\footnotetext{
${ }^{35}$ En 1979 la presencia femenina en el Congreso no fue superior a un 6\%, cifra similar a las convocatorias electorales del 82 y del 86 (4`5\% y 6’2\%, respectivamente). En el Senado, en el 82, fue de un 4`35\%. En los cargos ejecutivos de los principales partidos apenas supera en ningún caso el 30\%, estando en el caso del Partido Popular, Partido Nacionalista Vasco, Convergencia i Unió y Coalición Canaria oscilando en torno al 15 y el 27\%. Plan Estratégico 2008-2011 de Igualdad de Oportunidades; Instituto de la Mujer; Madrid. Habrá que ver qué datos deparan las elecciones celebradas el 20 de noviembre del 2011.
} 
también se consideran tradicionalmente de mujeres, ya sea el trabajo social, magisterio, psicología... y, en menor medida, las carreras técnicas o científicas ${ }^{36}$.

- Pero, además, obtenemos las mejores puntuaciones en las oposiciones a las Administraciones Públicas y en las judicatura, por ejemplo, hoy día hay muchas más mujeres que acceden que hombres.

- Ocupan menos del 20\% de las cátedras universitarias y ninguna de las 172 áreas de conocimiento tiene mayor número de mujeres que de hombres según datos que se publicaron recientemente.

- Existen dos Academias, la de Ciencias Políticas y Morales y la de Jurisprudencia y Legislación en la cual no hay ninguna mujer entre sus integrantes.

- Y, podríamos continuar con otras estadísticas de, por ejemplo, la presencia o ausencia en los medios de comunicación, en los cuerpos de seguridad del Estado o en los sindicatos, por citar algunos.

Por tanto, se tienen razones para ser optimistas pero muchas para entender por qué es necesario seguir legislando, seguir trabajando a través, entre otros mecanismos, de los planes de igualdad. No se puede olvidar, si queremos entender qué ha posibilitado la existencia de estos en la esfera local, que España desde 1978 se define como un Estado autonómico o de las Autonomías, articulándose territorialmente en cuatro grandes niveles, a saber: el local, el autonómico, el nacional y el supranacional. Donde las normativas y las políticas públicas se implementan a través del traspaso de competencias regulado en la Constitución y en sus normas de desarrollo. Primero se reguló a nivel nacional, posteriormente a nivel autonómico y en tercer lugar, a nivel local. En muchas ocasiones, mimetizándose las normativas, así como también las instituciones que se fueron creando para dar forma a lo recogido en el Título VIII del texto constitucional.

De ahí, que a veces, tal y como hemos mencionado en un apartado anterior, parezca que existen duplicidad de "esfuerzos” o de recursos empleados en la misma temática, incluso muchas críticas se encaminan hacia la falta de coordinación a la hora de afrontar determinadas problemáticas y al desconocimiento que se tiene sobre quién es el organismo o la entidad responsable de dar respuestas a algunas de las demandas de las mujeres. Pero, aunque no es del todo incierto que estos desajustes a veces se producen y que hay que intentar no perderse en la maraña político-administrativa que a veces suponen la existencia de distintas

\footnotetext{
${ }^{36}$ Aunque se da la paradoja de algunas áreas de conocimiento, como puede ser la ginecología y la obstetricia, donde no hay ninguna mujer catedrática.
} 
legislaciones sobre la igualdad ${ }^{37}$, de distintos planes de igualdad - nacionales, autonómicos, locales - de distintas medidas encaminadas a la supresión de la situación de desventaja de las mujeres, hemos de considerar como elemento de justicia resaltar su existencia. Porque entendemos que no son distorsiones del sistema, sino que debe aplicarse cada uno de ellos según si la política pública ante la que nos encontremos deba ser implementada y ejecutada por una autoridad local, autonómica y/o nacional. Sin olvidar, además, la transversalidad que los temas de igualdad de género deben tener en los distintos organismos de la administración pública española.

El siguiente paso es intentar exponer cómo se ha llegado hasta aquí, con qué se cuenta y cuál es la normativa que ha dado lugar a la necesidad de trabajar en dichos planes a las entidades locales (Molina Hermosilla, O, 2009). En el caso español, el movimiento feminista ha tenido menor impulso que en otros países europeos en cuanto al número de mujeres que se han conseguido movilizar, pero algunas en particular, con nombres y apellidos y determinadas fuerzas políticas desde el comienzo de la transición y, sobre todo, a partir de la década de los 80, convirtieron el tema de la reivindicación de la igualdad en una de sus banderas. Lo cual, conllevó a que el mismo fuera entrando, poco a poco, en la agenda gubernamental. Los temas que se consideraban "sólo de mujeres” o “propios de la esfera privada”, pasaron a ser de interés general, tal vez, el más llamativo al día de hoy por la repercusión mediática y social, sea el de la violencia de género, el que algunos llaman el terrorismo doméstico ${ }^{38}$. En este sentido, la llegada en 1982 del PSOE al gobierno, supuso un punto de inflexión para algunas de las medidas que se iban a empezar a implementar en relación a esta temática. Siendo la creación del Instituto de la Mujer en 1983, uno de los momentos más importantes (Tabla 1). Debido a que fue la institucionalización de lo que se conoció y se sigue conociendo como la feminización institucional o de Estado. En este sentido, en la siguiente tabla se pueden apreciar distintos hitos que han marcado un avance en cuanto a la visibilización de las cuestiones de igualdad de género en la agenda institucional del Gobierno español y a la estructuración de estas cuestiones en los organigramas ministeriales. Siendo el punto de llegada, la creación del Ministerio de Igualdad. Posteriormente, el Instituto tendría sus

\footnotetext{
${ }^{37}$ Por ejemplo, podemos mencionar la existencia de una Ley de Igualdad a nivel nacional, aplicable a todo el territorio español y una ley de igualdad de la Comunidad autónoma andaluza, aplicable sólo en dicha comunidad. Hay que aclarar, que las leyes autonómicas nunca podrán regular en contra de lo regulado a nivel nacional. Ni las locales en contra de las autonómicas y/o las nacionales. Lo mismo ocurre con los planes de Igualdad, los nacionales tienen supremacía normativa-jerárquica sobre los autonómicos. Y éstos, en sus respectivas Comunidades Autónomas, sobre los locales que conformen dicha realidad autonómica.

38 El Diario "El Mundo" publicó un suplemento sobre violencia de género bajo el título de “Terrorismo doméstico": <http://www.elmundo.es/documentos/2004/06/sociedad/malostratos/alerta.html>. (revisado en noviembre del 2011).
} 
homólogos a nivel autonómico, lo mismo que ocurrirá con los planes de Igualdad: primero se realizaron e implementaron a nivel nacional, luego autonómico y finalmente, local.

Tabla 1:

\begin{tabular}{|c|c|}
\hline \multicolumn{2}{|r|}{25 AÑOS DEL INSTITUTO DE LA MUJER (1983-2008) } \\
\hline 0 & Creación del Instituto de la Mujer (Ley 16/1983) \\
\hline 0 & $\begin{array}{l}\text { Promulgación del RD (1456/84) por el que se aprueba el reglamento del } \\
\text { organismo de la estructura necesaria para el cumplimiento de sus fines (1984) }\end{array}$ \\
\hline 0 & $\begin{array}{l}\text { Creación del Consejo Rector, órgano esencial del Instituto de la Mujer } \\
\text { constituido por doce representantes ministeriales, seis personas de acreditada } \\
\text { trayectoria a favor de la igualdad y presididas por el ministro de Cultura y, } \\
\text { posteriormente, de Asuntos Sociales (1985) }\end{array}$ \\
\hline 0 & $\begin{array}{l}\text { Apertura del Centro de Documentación del Instituto como desarrollo de la ley } \\
\text { 16/1983 de creación del organismo autónomo Instituto de la Mujer, que } \\
\text { establecía como una de sus funciones "recopilar información y documentación } \\
\text { relativa a la mujer, así como la creación de un banco de datos actualizado que } \\
\text { sirva de base para el desarrollo de las funciones y competencias del Instituto" } \\
\text { (1985) }\end{array}$ \\
\hline 0 & $\begin{array}{l}\text { Promulgación del RD 791/1988, por el que se determina la estructura orgánica } \\
\text { inicial del Ministerio de Asuntos Sociales, incluyendo al Instituto de la Mujer } \\
\text { dentro de esta estructura (1988) }\end{array}$ \\
\hline 0 & $\begin{array}{l}\text { Relevo en la dirección del Instituto de la Mujer, fruto de la remodelación } \\
\text { ministerial y creación del Nuevo Ministerio de Asuntos Sociales, que asume } \\
\text { competencias hasta entonces pertenecientes a Justicia, Trabajo y Cultura }\end{array}$ \\
\hline 0 & $\begin{array}{l}\text { Promulgación del RD 979/1989, por el que se modifica parcialmente el RD } \\
\text { 1456/1984, de } 1 \text { de agosto, por el que se aprueba el Reglamento del Organismo } \\
\text { Autónomo Instituto de la Mujer (1989). }\end{array}$ \\
\hline 0 & $\begin{array}{l}\text { Promulgación del RD 2129/1993, por el que se modifica la estructura orgánica } \\
\text { del Ministerio de Asuntos Sociales (1993) }\end{array}$ \\
\hline 0 & $\begin{array}{l}\text { Cambios en el gobierno tras la victoria del PP en las elecciones. Promulgación } \\
\text { del RD 839/1996, por el que se establece la estructura orgánica de varios } \\
\text { ministerios, entre ellos el de Trabajo y Asuntos Sociales. El Instituto pasa a } \\
\text { depender de este ministerio (1996) }\end{array}$ \\
\hline
\end{tabular}


o Promulgación del RD 74/1997 por el que se establece la nueva regulación y cambios organizativos del Instituto de la Mujer (1997)

o Creación del Ministerio de Igualdad, (2008)

Fuente: Astelarra, Judith (2005): “Veinte años de políticas de Igualdad”; Ed. Cátedra Feminismo; Madrid.

A partir de los años 80, al mismo tiempo que a nivel legislativo y gubernamental se van dando pasos en institucionalizar el feminismo y los logros de las mujeres, a nivel académico también se produce un importante repunte de este movimiento. Este dará cabida a muchas mujeres que en los años finales del franquismo y primeros de la transición habían compaginado su labor académica con la de participación en organismos y movimientos políticos y sociales. Este movimiento académico tiene como una de sus principales reivindicaciones y propuestas, la de acabar con la visión androcéntrica de la academia y la invisibilidad de las mujeres en muchas áreas del conocimiento. Se empiezan a crear Seminarios, Grupos de Investigación, se celebran Congresos, programas de doctorado, talleres, seminarios, jornadas de investigación... En definitiva, se empieza a declinar en femenino el saber científico, lo cual se ha mantenido con gran empuje hasta el día de hoy.

\section{¿Y qué pasa a nivel internacional?}

Pero, por encima de estas medidas nacionales, que ahora se tratarán con un poco más de detenimiento, trascendentales sin ninguna duda, España se encuentra formando parte de una sociedad internacional que condiciona sus legislaciones nacionales. Este nivel "supra" que a veces se olvida - o que algunos no quieren recordar - da lugar a un entramado normativo que ha diseñado y perfilado las políticas públicas de igualdad que regulan esta temática. Formar parte de distintas Organizaciones Internacionales y haber firmado y ratificado diversos acuerdos y Tratados Internacionales, obligan al gobierno español -sea cual sea su signo político - a adaptar o a aprobar nuevas legislaciones conforme a los principios y valores de esa Sociedad Internacional a la que aspira a formar parte. Así, si analizamos por ejemplo los Objetivos del Milenio, como uno de los muchos principios rectores aceptados por el gobierno español para guiar sus normativas, políticas y programas en el territorio español, el punto 3 abogaría por promover la equidad de género y la autonomía de la mujer porque, como ya hemos mencionado, la pobreza (y cada vez más) tiene rostro de mujer. Veamos este marco internacional: 
El derecho a la no discriminación y a la igualdad, fue reconocido por las Naciones Unidas, de la cual España forma parte desde el año 1955 - tras algunas escaramuzas, es cierto $^{39}$-, a través de distintos instrumentos, a saber:

- La Declaración Universal de los Derechos Humanos de 1948

- El Convenio de las Naciones Unidas sobre Derechos Económicos, Sociales y Culturales y el de Derechos Civiles y Políticos del año 1966

- La Convención de las Naciones Unidas para la Eliminación de la Discriminación Racial del 1965

- El Convenio 111 sobre Discriminación de la Organización Internacional del Trabajo del año 1958.

- La Convención para la Eliminación de cualquier forma de discriminación contra las mujeres del año 1979

Así mismo, se han producido una serie de Conferencias en el seno de la mencionada Organización de las Naciones Unidas, que han dibujado los mínimos que habría que alcanzarse para poder lograr la plena igualdad de derechos y oportunidades y el medio para llegar a éstos, a saber:

- La I Conferencia Mundial sobre la condición Jurídica y Social de la Mujer. México 1975

- La II Conferencia Mundial sobre la condición Jurídica y Social de la Mujer. Copenhague 1980

- La III Conferencia Mundial sobre la Condición Jurídica y Social de la Mujer. Nairobi 1985

- Y, tal vez, la más conocida: la IV Conferencia Mundial sobre la Condición Jurídica y Social de la Mujer, Beijing o Pekín 1995.

o En esta última, la mujer dejó de ser el foco central para pasar a serlo el tema del género, es decir, se focalizó el debate en temas que iban más allá de las diferencias biológicas entre hombres y mujeres, para ahondar en las

\footnotetext{
${ }^{39}$ Cuando en España acaba la guerra civil y triunfa el régimen franquista, se produce un período de aislamiento internacional y autarquía consecuencia de las diferencias de regímenes políticos existentes en Europa - sobre todo tras la II Guerra Mundial - y España. A partir del año 1953, con la firma de los Acuerdos con la Santa Sede y los Acuerdos para la existencia de Bases norteamericanas en territorio español y, sobre todo, de 1955 con el reingreso en la ONU, España comienza a volver a integrarse lentamente en el escenario europeo e internacional.
} 
construcciones y significados culturales de las mismas. Esta Conferencia se ha convertido en la principal referencia para considerar dos principios de obligado cumplimiento a la hora de trabajar en la lucha por la igualdad:

- La transversalidad o mainstreaming ${ }^{40}$ : Promover la perspectiva de género en la elaboración, aplicación y seguimiento de todas las políticas, medidas y acciones realizadas.

- El empoderamiento: Promover el acceso de las mujeres a las toma de decisiones en todas las escalas, fortaleciendo su autonomía y aumentando sus oportunidades. También se aplica a la toma de conciencia del poder que, individual y colectivamente, ostentan las mujeres y que tiene que ver con la recuperación de su propia dignidad como personas.

En dicha Conferencia se aprueba lo que se conoce como Plataforma de Acción de Beijing, la cual será revisada en otras dos reuniones:

1. Beijing + 5: La mujer en el año 2000: igualdad entre los géneros, desarrollo y paz en el siglo XXI. Realizada en Nueva York (2000)

2. Beijing + 10: Revisión y Evaluación de la anterior Declaración. Nueva York (2005)

Pero es que, además, no podemos olvidarnos que España pertenece desde el año 1986 a la Unión Europea ${ }^{41}$. La entrada en la Organización de la mano del Gobierno socialista liderado por Felipe González, fue el espaldarazo definitivo de las democracias europeas a un país que había sufrido cuarenta años de régimen dictatorial. En lo tocante a la temática que aquí nos interesa, al pasar a formar parte de la Unión Europea, España acepta incluir el acervo comunitario $^{42}$ y adaptar las legislaciones y las normativas españolas a las que venían dictadas

\footnotetext{
${ }^{40}$ Recogido en la Carta Europea para la Igualdad de Mujeres y Hombres en la vida local (CCRE). Según el Plan Estratégico 2008-2001, supone la integración de la perspectiva de género en el conjunto de políticas, considerando, sistemáticamente, las situaciones, prioridades y necesidades respectivas de mujeres y hombres, con vistas a promover la igualdad entre ambos sexos y teniendo en cuenta, activa y abiertamente, desde la fase de planificación, sus efectos en las situaciones respectivas de unas y otros cuando se apliquen, supervisen y evalúen.

${ }^{41}$ España había intentado entrar en la actual Unión Europea desde la década de los sesenta del siglo XX, pero fueron rechazados sus intentos debido a la existencia de un sistema político no democrático. No fue sino hasta la reinstauración de la democracia en el año 75, cuando se comienzan a tener negociaciones para conseguir ser miembro de Pleno derecho de la, en ese momento, Comunidad Económica Europea.

${ }^{42} \mathrm{El}$ acervo comunitario comprende la base común de derechos y obligaciones que vincula al conjunto de los Estados miembros de la Unión Europea, está en evolución constante y engloba: el contenido, los principios y los objetivos políticos de los Tratados; la legislación adoptada en aplicación de los Tratados y la jurisprudencia del Tribunal de Justicia; las declaraciones y resoluciones adoptadas en el marco de la Unión; los actos en materia de
} 
por los organismos europeos, entre ellas y como no podía ser menos, las referentes a la igualdad. En este sentido, dicha Organización tiene dentro de los pilares de su funcionamiento, los principios de igualdad de trato y de no discriminación. Aunque ya desde el Tratado Constitutivo de Roma del año 1957 se recogía este principio de igualdad ${ }^{43}$, interesa, sobre todo, destacar: "La Carta de los Derechos Fundamentales de la Unión Europea”; “La Recomendación del Consejo de diciembre del 96”, relativa a la participación equilibrada de mujeres y hombres en la toma de decisiones; "La Estrategia Marco Comunitaria sobre la Igualdad entre Hombres y Mujeres (2001-2005)” adoptada por la Comisión Europea en el año 2000, cuyo objetivo es introducir la dimensión de la igualdad de oportunidades en todas las políticas y acciones realizadas en el ámbito comunitario y en las Estados Miembros. Para ello, se articula la actividad en torno a 5 ámbitos de intervención interdependientes, cada uno de ellos con distintos objetivos operativos, a saber:

1. La vida económica

2. La igualdad de participación y representación

3. Los derechos sociales

4. La vida civil

5. Los roles y estereotipos masculinos y femeninos.

Política Exterior y de Seguridad Común; los actos acordados en materia de Justicia y Asuntos de Interior; los acuerdos internacionales celebrados por la Comunidad y los celebrados por los Estados miembros entre sí en el ámbito de las actividades de la Unión. Para mayor información véase: <http://europa.eu/legislation_summaries/glossary/community_acquis_es.htm>. (revisado en noviembre de 2011). ${ }^{43}$ Algunas fechas claves:

- Tratado de Roma, 1957: artículo 119: Los hombres y las mujeres deben recibir el mismo salario por el mismo trabajo

- 1981, La Comisión Europea crea un comité consultivo encargado de implementar y proponer acciones para la igualdad de oportunidades

- 1983, La Comisión organizó el trabajo en Programas de Acción Comunitaria

- $\quad$ 1984, se creó en el Parlamento Europeo, el Comité de Derechos de la Mujer

- De 1983 al 2000, se aprobaron 4 programas en esta dirección de favorecer la igualdad

- A partir del año 2000 comienzan las Estrategias Marco comunitaria sobre la igualdad entre hombres y mujeres, La última aprobada corresponde a 2010-2015 (aprobada en septiembre del 2010): La presente estrategia es fruto del plan de trabajo (2006-2010) para la igualdad entre las mujeres y los hombres. Recoge las prioridades definidas por la Carta de la Mujer, constituye el programa de trabajo de la Comisión y describe las acciones clave previstas entre 2010 y 2015. Asimismo, esta Estrategia establece una base para la cooperación entre la Comisión, las demás instituciones europeas, los Estados miembros y el resto de partes interesadas, en el marco del Pacto Europeo por la Igualdad de Género.

Para ver todos los temas relativos a igualdad de género en la Unión Europea, véase: <http://europa.eu/legislation_summaries/employment_and_social_policy/equality_between_men_and_wom en/index_es.htm>. (Revisado en octubre de 2011). 
Pero, por encima de todo, "La Carta Europea para la Igualdad de Mujeres y Hombres en la Vida Local ${ }^{44 » ”}$. En ésta, se afirmaba que la igualdad de mujeres y hombres es un derecho fundamental para todas las personas y constituye un valor capital para la democracia. Para que se cumpla plenamente, no sólo se debe reconocer legalmente, sino también ejercer efectivamente e implicar a todos los aspectos de la vida, políticos, económicos, sociales y culturales. A pesar de los numerosos ejemplos de un reconocimiento formal y de los programas realizados, la igualdad de mujeres y hombres en la vida cotidiana no es una realidad. Los hombres y las mujeres, no disfrutamos de los mismos derechos en la práctica. Persisten desigualdades políticas, económicas y culturales, cuyos ejemplos más notorios son las diferencias salariales y la menor representación política de las mujeres. Consecuencia, sobre todo, de las estructuras sociales fundamentadas en numerosos estereotipos que están en la familia, la educación, la cultura, los medios de comunicación, el mundo laboral, la organización social... En este sentido, este texto recoge cómo las autoridades locales y regionales son las esferas de gobierno más próximas a la población, representando los niveles de intervención más adecuados para combatir la persistencia y la reproducción de las desigualdades y para promover una sociedad verdaderamente igualitaria. Estos gobiernos, en sus ámbitos de competencia y colaborando con el conjunto de actores locales, pueden emprender acciones concretas a favor de la igualdad de mujeres y hombres. Siendo el Principio de subsidiariedad fundamental a la hora de alcanzar esta igualdad, junto al de autonomía local y regional. Así se recoge en "La Carta de Autonomía Local del Consejo de Europa 1985”, donde se subraya el derecho y la capacidad efectiva de las colectividades locales para regular y administrar, en el marco de la ley, bajo su propia responsabilidad y en beneficio de sus poblaciones, una parte importante de asuntos públicos ${ }^{45}$. De ahí la importancia de que a estos niveles político-administrativos, se incorpore la dimensión del género.

La referida Carta tiene 6 principios fundamentales de actuación, a saber:

1. La igualdad de mujeres y hombres constituye un derecho fundamental

\footnotetext{
${ }^{44}$ Una Carta para que los gobiernos locales y regionales se comprometan a utilizar sus facultades y las de sus asociados a favor de una mayor igualdad. Fue redactada en el marco de un proyecto (2005-2006) llevado a cabo por el Consejo de Municipios y Regiones de Europa, en colaboración con numerosos socios. Tuvo el apoyo de la Comisión Europea, en el marco del $5^{\circ}$ programa de acción comunitaria para la igualdad de mujeres y hombres.

45 "La democracia local y regional han de permitir que se hagan las elecciones más apropiadas en relación con los aspectos más concretos de la vida cotidiana, tales como la vivienda, la seguridad, los transportes públicos, el mundo laboral o la sanidad. Igualmente, la plena implicación de las mujeres en el desarrollo y la aplicación de políticas locales y regionales permite que se tenga en cuenta, por las experiencias vividas, sus conocimientos y creatividad".
} 
2. A fin de asegurar la igualdad de mujeres y hombres, se debe tener en cuenta la discriminación múltiple y las desventajas que supone.

3. La participación equilibrada de mujeres y hombres en la toma de decisiones es un requisito para la sociedad democrática

4. La eliminación de los estereotipos de género es indispensable para la instauración de la igualdad de mujeres y hombres

5. Integrar la dimensión del género en todas las actividades de los gobiernos locales y regionales en necesario para que avance la igualdad de mujeres y hombres

6. Planes de acciones y programas con los recursos apropiados son herramientas necesarias para hacer avanzar la igualdad de mujeres y hombres.

Así mismo, tendríamos que mencionar la creación en el año 2005, por el Consejo de Municipios y Regiones de Europa de "la ciudad por la igualdad”, en donde se propone una metodología para la aplicación de políticas de igualdad de mujeres y hombres a nivel local y regional y "La Declaración Mundial de la Unión Internacional de Ciudades y Autoridades Locales de 1998” referidas a mujeres en el gobierno local.

El siguiente escalón es el ya mencionado nivel nacional. Como no podía ser de otro modo, en la Constitución Española del año 1978, se establecen los principios de igualdad y no discriminación como valores superiores del ordenamiento jurídico (art. 1 y 14) y se insta a los poderes públicos a promover las condiciones para que la igualdad sea real y efectiva (art. 9). Los distintos Institutos de la Mujer que se crean en la década de los 80 dentro del territorio español, tienen entre sus actividades, la realización de los Planes de Igualdad, los cuales son los instrumentos básicos para la articulación de las políticas de igualdad. Son un conjunto de objetivos y medidas tomadas y aprobadas por un gobierno y que deben llevar a cabo los diferentes departamentos gubernamentales en un determinado período de tiempo. A nivel nacional, hasta el momento, se han puesto en marcha cuatro Planes de Igualdad a través del Instituto de la Mujer, a saber:

- I Plan para la Igualdad de Oportunidades entre mujeres y hombres (1988-1990). Cuyo principal objetivo era asegurar la coherencia del ordenamiento jurídico con el principio de igualdad y no discriminación, eliminando para ello las disposiciones legales discriminatorias que existían en el ordenamiento penal y civil. Lo que se conoce como discriminación directa. 
- II Plan para la Igualdad de Oportunidades entre Mujeres y Hombres (1993-1995). Cuyo principal objetivo es pasar de la igualdad formal a la real, mediante las llamadas medidas de acción positivas en materia de educación, fomento y empleo.

- III Plan para la Igualdad de Oportunidades entre Mujeres y Hombres (1997-2000). El cual introduce los compromisos de la Plataforma de Acción de Beijing, sobre todo, la transversalidad o mainstreaming y las orientaciones del IV Programa de Acción Comunitaria.

- IV Plan para la Igualdad de Oportunidades entre Mujeres y Hombres (2003-2006). El cual ha incidido tanto en el principio de transversalidad como en las medidas de acción positiva.

En la actualidad, en la Ley de Igualdad, lo que se ha previsto es la implementación de un Plan Estratégico 2008-2011, con el que ya se está trabajando que vendrían a sustituir a los Planes de Igualdad del Instituto. Según Carlota Bustelo (Bustelo, 2004) los mencionados planes tienen una serie de características:

1. Concienciar a los poderes públicos sobre el problema de la igualdad

2. Mostrar el compromiso público ante el tema

3. Globalidad: tratan el problema de la igualdad desde diferentes ámbitos y sectores (empleo, educación, legislación, salud...)

4. Visión estratégica: definen períodos de tiempo, recursos económicos y humanos

5. Horizontalidad: Requieren la participación activa de diferentes departamentos y sectores gubernamentales como condición necesaria para promover el mainstreaming en todas las políticas públicas

6. Participación: en el proceso de elaboración se incluye algún tipo de participación de grupos de mujeres

7. Seguimiento y evaluación: necesarias para saber si el contenido de los planes ha servido o no para cambiar la situación de desigualdad que los originó.

En los planes, se recogen las distintas áreas de actuación, los objetivos, acciones y/o medidas para realizarlas y los organismos que deberán ejecutar las mismas. Posteriormente las Comunidades Autónomas también elaboraron sus propios planes de igualdad y, en los últimos años, se han unido a ello las entidades locales. En la Ley de Igualdad, en su artículo 21.2, se menciona que: las Entidades Locales integrarán el derecho de igualdad en el 
ejercicio de sus competencias y colaborarán a tal efecto, con el resto de las Administraciones Públicas. Además, en el artículo 22, dice que: Con el fin de avanzar hacia un reparto equitativo de los tiempos entre mujeres y hombres, las corporaciones locales podrán establecer Planes Municipales de organización del tiempo de la ciudad.

En todos los planes, los cuales han seguido para su elaboración las directrices marcadas por el IV Programa de la Unión Europea y por la Estrategia Marco Comunitaria anteriormente mencionado, aparecen los siguientes objetivos:

- Introducción de la perspectiva de género en las políticas públicas

- Derechos e igualdades de oportunidades

- Empleo y participación económica

- Conciliación de la vida familiar y laboral: corresponsabilidad

- Exclusión social, atención a la diversidad

- Violencia de género

- Educación, cultura, deporte y medios de comunicación

- Salud y calidad de vida

- Mujeres rurales

- Participación socio-política

- Cooperación

Como ya se ha mencionado, la Administración Local es la más cercana al ciudadano y, además, es percibida por éste como tal. De ahí, que uno de sus principales retos sea el de incluir y lograr entre sus objetivos la igualdad entre hombres y mujeres. Para ello, deberá tanto poner en marcha políticas públicas de igualdad, como aplicar la transversalidad o mainstreaming en todas y cada una de las actividades municipales. Esto aparece recogido en Ley 7/85 de 2 de abril, reguladora de las Bases de Régimen Local, en su artículo 28, se dice que: los municipios pueden realizar actividades complementarias de las propias de otras Administraciones Públicas y, en particular, las relativas a la educación, la cultural, la promoción de la mujer, la vivienda, la sanidad y la protección del medio ambiente ${ }^{46}$.

Desde ese momento, 1985, los grandes municipios comienzan a incorporar Concejalías de la mujer en sus gobiernos municipales y, al día de hoy, raro es encontrar alguno que no cuente con dicha área de trabajo. Son éstas las que promueven y ponen en

\footnotetext{
${ }^{46}$ La redacción de este artículo se ha mantenido tras las dos modificaciones de la Ley Básica de Régimen Local: la Ley 11/1999 de 21 de abril y la Ley 57/2003 de 16 de diciembre de Medidas para la modernización del Gobierno Local.
} 
marcha servicios especializados para mujeres en el ámbito social, psicológico y jurídico. Aunque muchas veces es más la voluntad política de aquellas y aquellos que trabajan en las mismas que la posibilidad de actuación y el margen de maniobra con el que cuentan. Es más, para saber las particularidades de estos temas, sólo hace falta hacer un recorrido por las denominaciones y los “emparejamientos" que en muchas ciudades y pueblos tienen las concejalías que se ocupan del tema de la mujer y de los planes de igualdad. Es a partir de la década de los 90, por tanto, que se da un paso más y se empiezan a elaborar Planes de Igualdad, primero en los grandes municipios, extendiéndose en la actualidad a un número importante de éstos en toda la geografía española.

En el año 2006, se firmó un Convenio de colaboración entre el Instituto de la Mujer y la Federación Española de Municipios y Provincias para la puesta en marcha de un Programa Experimental para el desarrollo de políticas municipales en las que se aplique la perspectiva de género. Así mismo, existe un acuerdo con el Ministerio de Trabajo y Asuntos Sociales para promover planes de igualdad en los ámbitos locales y la Comisión de Igualdad tiene un grupo de trabajo en Igualdad. El mismo, ha realizado "Una guía para elaborar planes de igualdad", como elemento de apoyo para las entidades locales en esta temática. Según se recoge en la misma, los Gobiernos Locales han sido pioneros en la puesta en marcha de las medidas prácticas que consolidan el derecho a la igualdad. (...) Las Entidades Locales (...) se hicieron eco de las reivindicaciones de las mujeres y pusieron en marcha servicios y apoyos públicos para mejorar la calidad de vida de vecinas. Según la Federación, debido a la diversidad de la realidad socio-económica de los municipios, se deberán tener en cuenta los siguientes aspectos a la hora de la implementación de las políticas locales de igualdad:

- Visibilizar, especificar y analizar las distintas situaciones de hombres y mujeres, sus relaciones y las consecuencias que de ello se ocasionan

- Tratar los problemas de forma integral y radical

- Generar propuestas que de verdad tengan posibilidades efectivas de producir cambios en la realidad material y en la simbólica

- Tener en cuenta tanto las necesidades prácticas como las estrategias de género, más centradas en cambiar la relación entre los géneros y la situación de discriminación de las mujeres. 
Para ello, la redacción del Plan es central, mencionando en el mismo los objetivos y los compromisos que se buscan alcanzar. Siendo necesario contar con profesionales formados y formadas en estas realidades. En la guía se recoge que los Planes de Igualdad son planes de trabajo que intentan incidir en el problema social de la desigualdad entre hombres y mujeres y no en "problemas de mujeres", es decir, remarcan que los mismos se entienden como problemas de desigualdades de género. Es un plan conjunto de toda la corporación, y no sólo de un área o concejalía como a veces se ha pretendido transmitir a la ciudadanía. Lo cual supone un grave error a la hora de afrontar esta temática ya que no se puede aislar lo que le ocurre a las mujeres, sus derechos, sus reivindicaciones, sus necesidades, de aquellas de la sociedad en la cual desarrollan su vida. Los Planes de igualdad se convierten en un compromiso adquirido para cambiar la realidad de desigualdad entre hombres y mujeres en el municipio, donde el sexo de una persona no predetermine qué puede hacer y no puede hacer, qué puede o no puede tener, en definitiva, cuál es su papel en la sociedad y cuáles sus derechos y deberes. Aplicando la perspectiva de género a todo lo que se hace en el municipio, construyendo una nueva cultura y abordando los problemas de injusticia que han provocado estas diferencias en los roles asignados y asumidos. Sobre todo, por tanto, lo que se remarca, es que estos planes han de servir para hacer cambios, que deben ser no sólo un conjunto de objetivos y medidas bien diseñados, políticamente correctos y con buenas intenciones, sino que su fin último, la razón de ser de los mismos, es conseguir que "mañana”, eso a lo que le llamamos el futuro, sea distinto. Y no sólo distinto, sino mejor para las mujeres, en particular, y para la sociedad, en general.

Realmente la pregunta que tendríamos que realizar llegados a este punto es: ¿la cuestión del género, de la paridad, de la presencia de la mujer en la vida pública es por convicción de la sociedad española, por oportunidad política o por cuestión de moda? A lo que habría que añadir: ¿Consideran que alguien alguna vez se ha preguntado si el que los hombres siempre hayan copado todas las esferas de la sociedad era porque todos los que la conformaban pensaban que así tenía que ser (incluidas las mujeres) o porque en ese momento era lo políticamente correcto, porque tal y como se ha dicho en relación a las mujeres, electoralmente daba mayor rédito político que así fuera, porque era lo que tenía que ser? Cosas que eran realizadas por hombres, se daban por bien realizadas, por ser lo normal, lo correcto, lo obvio... pero ahora que se han abierto espacios para las mujeres, hay que empezar a plantearse el por qué de las diferencias, hay que buscar respuesta a cuestiones reivindicadas durante siglos, hay que intentar entender por qué las cosas son así a diferencia de como eran hace unos años... 
Mientras, sigamos pensando en lo que para algunos y algunas eran imposibles hace años, décadas o a veces tan sólo semanas o días. Como decía una feminista chilena, "hay que pararse en el umbral de la utopía para obligarse a la realidad a acercarse a ella”. En estos momentos es impensable dar respuesta a través de una valoración global de lo conseguido en todos y cada uno de los municipios donde se han implementado los planes de igualdad, puesto que la casuística es inabarcable. Debemos valorar de manera positiva su existencia, la toma de decisiones de la entidad local que dio lugar a los mismos y los análisis de las situaciones que han permitido diseñar programas, acciones y objetivos para lograr la igualdad de género. Algunos llevan años funcionando, incluso décadas, otros apenas están dando los primeros pasos, en muchos casos, siguen siendo proyectos aún por concretar. Además, la situación económica de crisis en la que estamos inmersos, está dando lugar a que algunas de las medidas que venían previstas en los mismos, se hayan visto paralizadas o adaptadas a las nuevas realidades. Y, en otros casos, las evaluaciones que debían darnos respuestas e indicaciones en aquellos lugares donde habían comenzado a trabajar, se han paralizado o han quedado reducidas a meras actividades de coste-beneficio.

Podría parecer que el proceso está siendo muy lento, pero no debemos olvidar que el nivel local ha sido el último en ponerse a trabajar en la igualdad tras las actuaciones desarrolladas en el nacional y en los autonómicos. Y, como se expuso al comienzo del trabajo, en estas cuestiones, los cambios para poder apreciarse requieren un tiempo que aún no se puede contabilizar para ver su efectividad en el caso que nos ocupa. Pero debe considerarse un logro su existencia, ya que la situación de la mujer en España hace treinta años hacía impensable una sociedad y unas normativas como las actuales, por mucho que aún quede un largo camino por recorrer.

El viraje ideológico que se está produciendo en España en el último año en todas las esferas gubernamentales, será el verdadero elemento a tener en cuenta para poder responder a los interrogantes anteriormente planteados. Para comprobar si estos cambios y estos logros han calado en la creación de una nueva identidad igualitaria en la ciudadanía, más allá de ser sólo - o sobre todo - la bandera o el baluarte de un partido o movimiento político. Cuando la igualdad de género y las políticas y medidas que lo postulan dejen de ser sólo esgrimidas como un logro o una aspiración de algunos sectores sociales, y pase a ser un principio rector de la sociedad en su conjunto, habremos consolidado esas reivindicaciones y luchas en las que tantas voces fueron silenciadas a lo largo de la historia. Estos temas dejarán de ser utilizados como un arma política arrojadiza por las distintas fuerzas políticas y se habrá normalizado que el poder ya no es "sólo cosa de hombres”. 


\title{
OS PLANOS DE IGUALDADE NA ESPANHA: Respostas locais com perspectiva de gênero a problemas globais
}

\section{Resumo}

O objetivo do presente trabalho é apresentar uma reflexão sobre o que significou a implementação das políticas públicas de igualdade na Espanha desde a restauração democrática, especialmente em nível administrativo local e através dos conhecidos planos de igualdade. Perguntamos se todos esses avanços que dizem ter conseguido as mulheres ao serem consideradas cidadãs de pleno direito, realmente têm se transformado em ações concretas ou seguem imperando os papéis de gênero e estereótipos que as têm deixado invisíveis como coletivo e como sujeitos individualizados. Lembrar de onde viemos sempre nos ajuda a não esquecer onde estamos e quantas lágrimas, esforços e sacrifícios nos custaram para sermos ouvidas e tidas em conta. Este trabalho visa essa revisão, no âmbito do Estado espanhol.

Palavras-chave: Políticas públicas de igualdade. Estudos de gênero. Direitos humanos. Planos de igualdade. Administração local.

\section{EQQUITY PLANS IN SPAIN: Local answers with gender perspective to global problems}

\begin{abstract}
The purpose of this study is to present the assessment of how the implementation of equity public policies impacted Spain since the restoring of democracy, especially at the local administrative sphere and through known equity plans. It is arguable if these advancements that supposedly granted women the right of full citizenship actually have been translated into concrete actions, or if the gender role and stereotype still prevail, rendering them invisible both as a group and as individuals. Remembering our origins always prevents forgetting where we stand and how many tears, effort and sacrifices were endured before we were heard and taken into account. This review addresses the work carried out in Spain.
\end{abstract}

Key words: Equity Public Policies; Gender studies; Human rights; Equality Plans; Local Administration.

\section{Referências}

AGUILAR, L. Problemas públicos y agenda de gobierno. Ed. Miguel Ángel Porrúa. México D.F. 1993.

ALBERDI, C. El poder es cosa de hombres, Edición de Lucía Méndez, Madrid: Editorial La esfera biografías, 2001.

ALCAÑIZ, M. "Conciliación entre las esferas públicas y privada: ¿hacia un nuevo modelo en el sistema de género”? en Sociología, problemas y prácticas; n 44; Lisboa; Portugal, 2004. 
ÁLVAREZ, M. T. Ellas mismas. Mujeres que han hecho historia contra viento y marea; Madrid. Editorial La Esfera de los Libros, 2005.

AMORÓS, C. (Dir.). Diez palabras clave sobre mujer; Editorial Estella; Estella; Navarra; Editorial Verbo Divino, 1995.

ASOCIACIÓN “Mujeres en la transición democrática” (1999): Españolas en la transición. De excluidas a protagonistas (1973-1982). Madrid: Biblioteca Nueva.

ASTELARRA, J. Veinte años de políticas de igualdad; Madrid. Editorial Cátedra Feminismos, 2005.

BLÁZQUEZ, B. (2010): “Los estudios de género desde una visión politológica: la perspectiva de género como generadora de nuevos ámbitos de conocimiento y reflexión en España” en Delgado de Smith, Y. y María Cristina González (coord.): Mujeres en el mundo:

colonialismo, racismo, redes, violencia de género, política y ciudadanía. Lainet. Valencia. Venezuela.

BUSTELO, M. La Evaluación de las políticas de género en España; Madrid; Ed. Catarata, 2004.

CAMPILLO IBORRA, N. (Coord). Género, ciudadanía y sujeto político. (En torno a las políticas de igualdad); Valencia; Institut Universitari d'Estudis de la Dona; Universidad de Valencia, 2000.

Carta Europea para la Igualdad de mujeres y hombres en la vida local; Consejo de Municipios y Regiones de Europa y sus socios (CCRE-CEMR).

CONSEJO DE EUROPA. Mainstreaming de género. Marco conceptual, metodología y presentación de "buenas prácticas". Informe final de las actividades del Grupo de especialistas en mainstreaming (EG-S-MS)”; Madrid; Instituto de la Mujer, Ministerio de Trabajo y Asuntos Sociales, Serie Documentos, N² 28, 1999.

CUESTA, J. (dir.): Historia de las mujeres en España: siglo XX. Madrid: Instituto de la Mujer. 2003.

DE LOS SANTOS, D. Las mujeres que no amaban a los hombres. El régimen feminista en España; Córdoba; Ed. Almuzara, 2010.

DIZ OTERO, I. y LOIS GONZÁLEZ, M. (eds). Mujeres, instituciones y política; Barcelona y Santiago de Compostela; Edición Bellatera y Escola Galega de Administración Pública, 2007.

DUBY, G. y PERROT, M. (dir). Historia de las mujeres. El siglo XX; Barcelona; Editorial Taurus, 2003.

Estrategia Marco Comunitaria sobre la Igualdad entre hombres y mujeres (2001-2005).

Federación Española de Municipios y Provincias. Documento marco para la gestión de los planes de igualdad; <http://www.femp.es>. 2006. 
FOLGUERA, P. (ed). El feminismo en España. Dos siglos de historia. Fundación Pablo Iglesias, Madrid. 2007.

GAGO, C. Atlas de la situación de la mujer en el mundo; Ed. SM, 2006.

Guía para elaborar Planes de Igualdad, Federación Española de Municipios y Provincias.

GRUPO DE ESPECIALISTAS EN MAINSTREAMING. Mainstreaming de Género; Madrid; Instituto de la Mujer, 1999.

INSTITUTO DE LA MUJER. La mujer y la Constitución Española de 1978; Madrid, Estudios $n^{\circ}$ 61, 1990.

INSTITUTO DE LA MUJER. Mainstreaming de género: marco conceptual, metodología y presentación de “buenas prácticas”; Serie Documentos, n² 28; Madrid, 2001.

LAGARDE, M. Género y feminismo. Desarrollo y democracia; Madrid; Editorial Horas y horas, 1996.

Ley 7/85 de 2 abril, reguladora de las Bases de Régimen Local.

Ley 33/99, de conciliación de la vida familiar y laboral de las personas trabajadoras.

Ley 30/2003 sobre medidas para incorporar la valoración del impacto de género en las disposiciones normativas que elabora el Gobierno.

Ley Orgánica 1/2004, de 28 de diciembre, de Medidas de Protección Integral contra la Violencia de Género.

Ley Orgánica 3/2007 de 22 de marzo para la Igualdad Efectiva de Mujeres y Hombres.

LOMBARDO, E. "El Mainstreaming de género en la Unión Europea” en Revista Jurídica de Igualdad de Oportunidades entre Mujeres y Hombres (Aequalitas), vol- 10-15, MayoDiciembre 2003, Pp 6-11. Aragón.

MARTÍNEZ, C.; GUTIÉRREZ, P. y GONZÁLEZ, P. (eds.): El movimiento feminista en España en los años 70. Madrid: Cátedra. 2009.

MENÉNDEZ, I. El cuarto poder: ¿un poder de mujeres?; Oviedo; Editorial Milenta, 2003.

MOLINA HERMOSILLA, O. (Editora). Gestión práctica de Planes de Igualdad; Albacete; Editorial Bormazo, 2009.

MURILLO, S. Relaciones de poder entre hombres y mujeres; Madrid; Ministerio de Trabajo y Asuntos Sociales; Federación de Municipios y Provincias, 2000.

PÉREZ SÁNCHEZ, M. (Coord). Análisis de Políticas Públicas; Granada; Editorial Universidad de Granada, 2006.

Plan Estratégico 2008-2011 de Igualdad de Oportunidades; Instituto de la Mujer, Madrid. 
SERRA YOLDI, I (DIR). La evaluación de Políticas Públicas: los planes de igualdad; Valencia; Fondo Social Europeo, Generalitat Valenciana, 2003.

SCOTT, J. (2005). O enigma da igualdade en Revista de Estudos Feministas, $\mathrm{n}^{0}$ 13, (1), Enero-Abril: Pp 11-30.

VALIENTE, C. Guía Práctica para la elaboración de planes y políticas de igualdad; Madrid; Federación Española de Municipios y Provincias, 1998.

VALVÁRCEL, A. L La política de las mujeres; Madrid; Editorial Cátedra, 1997.

VVAA. Estudio comparativo de los planes de igualdad de oportunidades entre mujeres y hombres autonómicos y nacional; Madrid; Ministerio de Trabajo y Asuntos Sociales; Secretaría para la Igualdad de oportunidades e Instituto de la Mujer, 2005. 